\title{
NAS PORTAS DO PANDEMÔNIO: CYBERNETIC CULTURE RESEARCH UNIT E A INVENÇÃO DA TRADIÇÃO MÁGICA
}

\section{Step into the Pandemonium: On Breathing Life into the CCRU's Invented Magical Traditions}

\author{
Willian Perpétuo Busch ${ }^{1}$ \\ Robert Cluness ${ }^{2}$
}

\section{RESUMO}

Neste artigo trataremos do Ccru: Cybernetic Culture Research Unit visando contextualizar as particularidades que orbitaram a sua origem, bem como indicaremos alguns dos seus desdobramentos. Partiremos duma análise e apresentação inicial acerca dos usos feitos pelos grupos esotéricos contemporâneos, visando elucidar como a criação de uma narrativa de tradição e de conexão com o passado é fundamental no processo de legitimação. Na sequência, adentraremos no Ccru tendo em vista a 'interface' entre a sua proposta teórica que se somou a iniciativas externas e gerou uma estratégia discursiva inédita e distinta.
\end{abstract}

Palavras-chave: Cybernetic Culture Research Unit; Esoterismo; Cibernética; Realismo Especulativo; Hiperstição.

\begin{abstract}
In this article we will deal with the Ccru: Cybernetic Culture Research Unit aiming to contextualize the particularities that orbited its origin, as well as to indicate some of its developments. We will start from an analysis and initial presentation about the uses made by contemporary esoteric groups, aiming to elucidate how the creation of a narrative of tradition and connection with the past is fundamental in the process of legitimization. In the sequence, we will enter Ccru in view of the 'interface' between its theoretical proposal that added to external initiatives and generated an unprecedented and distinctive discursive strategy.
\end{abstract}

Keywords: Cybernetics Culture Research Unit; Esoteric; Cybernetics; Speculative Realism; Hyperstition.

\section{Introdução}

A revindicação por uma tradição e um mito de origem perpassam os discursos científicos contemporâneos, bem como no campo dos saberes esotéricos, uma vez que é mediante esse processo que se produz narrativas de legitimidade, autoridade e poder. Olav Hammer $^{3}$ argumentou que esse ato de construir uma mitologia embasada e vinculada numa tradição de sabedoria é utilizado por ocultistas, tanto grupos quanto indivíduos, para reivindicar

\footnotetext{
Doutorando em História pela Universidade Federal do Paraná

Doutorando em Estudos Culturais pela University of Iceland

HAMMER, Olav, Claiming Knowledge: Strategies of Epistemology from Theosophy to the New Age, Brill: Leiden, 2004
} 
a veracidade de suas afirmações. Diferentes estratégias podem ocorrer, como a descoberta de “textos arcanos” que contém instruções mágicas, sistemas cosmológicos, relatos de "histórias ocultas” (que frequentemente remontam a Antiguidade). O resultado é uma prática retórica que serve para legitimar a sua autoridade, enquanto confere uma aura de autenticidade. ${ }^{4}$

Inquirições acadêmicas acerca da discursividade esotérica evidenciariam os usos e reivindicações das "tradições", considerando tanto os seus aspectos internos e externos. Percebeu-se a prática recorrente nos mais variados grupos ocultistas contemporâneos, desde o neopaganismo, passando pelo druidismo, bem como Nova Era entre outros; e serve como um elo entre o presente e o passado. A historiografia demonstrou que este processo de conexão mediado pela tradição e prática são invenções históricas recentes. ${ }^{5}$

Olav Hammer ${ }^{6}$, inclusive, demonstrou que a construção ou invenção de tais tradições não é um fenômeno unicamente contemporâneo. Teosofia, Antroposofia, Telema, A Ordem Hermética da Aurora Dourada, indo até o Rosicrucianismo do século XVII, são todos construções ou “invenções” de tradição através do sincretismo de vários elementos de saberes rejeitados e marginalizados, enquanto tomam inspiração de várias fontes culturais de um período histórico situado. Desta forma, a reestruturação e reconciliação do "saber antigo" através duma visão de mundo situada e mesclada por um panorama cultural demarca que os ocultistas são resultados do processo de inovação e renovação. Neste sentido, a escrita historiográfica e a invenção esotérica convergem na:

Dependência com relação a um poder estabelecido em outra parte, domínio das técnicas concernentes às estratégias sociais, jogo com os símbolos e as referências que legitimam a autoridade diante do público são as relações efetivas que parecem caracterizar esse lugar de escrita. ${ }^{7}$

Na esteira de Michel de Certeau destacamos a ideia que os discursos "enquanto falam da história, estão sempre situados na história” ${ }^{8}$. O diferencial dos discursos esotéricos

4 ASPREM, Egil; GRANHOLM, Kennet, Constructing Esotericisms: Sociological, Historical and Critical Approaches to the Invention of Tradition, in: ASPREM, Egil; GRANHOLM, Kennet (Orgs.), Contemporary Esotericism, Sheffield: Equinox, 2013, p. 25-48.

5 DAVIES, Own, The Oxford Illustrated History of Modern Witchcraft, Oxford: Oxford University Press, 2017; HARVEY, Graham, Inventing Paganisms: Making Nature, in: HAMMER, Olav; LEWIS, James (Orgs.), The Invention of Sacred Tradition and Claiming Knowledge, Cambridge: Cambridge University Press, 2007; GRANHOLM, Kennet, Sons of Northern Darkness: Heathen Influences in Black Metal and Neofolk Music, Numen, n. 58, p. 514-544, 2011.

6 HAMMER, Claiming Knowledge: Strategies of Epistemology from Theosophy to the New Age.

7 CERTEAU, Michel de, A Escrita da História, Rio de Janeiro: Forense Universitária, 1982, p. 21.

8 Ibid., p. 32. 
contemporâneos, quando comparados com os seus predecessores, diz respeito a sua relação deliberada, direta e consciente com os textos ficcionais e o arranjo occultural (ocultismo+cultura) que já se apresenta na sua gênese esotérica, servindo tanto como inspiração e/ou como fonte espiritual primária.

O povoamento ficcional se exemplifica com Harry Potter ${ }^{9}$, J.R.R. Tolkien ${ }^{10}$, Star Wars ${ }^{11}$, World of Warcraft ${ }^{12}$, Skyrim ${ }^{13}$, ou Matrix ${ }^{14}$, alguns dos vários exemplos de produções que são resignificadas por grupos ocultistas ou por novos agrupamentos religiosos, mobilizando uma nova narrativa que enquadra tanto o âmbito efêmero da occultura e confere formas novas e inesperadas para o cenário esotérico ${ }^{15}$. O resultado disto é um processo de corporificação que Simon O’Sullivan e David Burrows definiram como “ficcionalização”, isto é, "a escrita, a imaginação, a performance, ou quaisquer outras instâncias materiais de mundo, ou de corpos sociais que marcam trajetórias distintas daquelas engendradas pela organização dominante existente de vida atual ${ }^{16 ”}$. Visto desta forma, o esoterismo contemporâneo é a reconstrução da realidade consensual e a sua “re-presentação” através da manufatura de várias ficções e mitos que misturam a occultura 'pop’ com as narrativas históricas.

\section{Desenvolvimento}

A história do Ccru, Cybernetics Culture Research Unit, é peculiar e difusa. Um grupo de pesquisa interdisciplinar que surgiu e se manteve ativo no Reino Unido entre o fim da década de 1990 e o começo dos anos 2000, serve como um fascinante caso para o estudo da criação de tradições esotéricas a partir da ficcionalização.

9 COMPAGNONE, Vanessa; DANESI, Marcel, Mythic and Occultism Naming Strategies in Harry Potter, Names, v. 60, n. 3, p. 127-134, 2012.

10 COUTRAS, Lisa, Tolkien's Theology of Beauty: Majesty, Splendor, and Transcendence in Middle-Earth, New York: Palgrave Macmillan, 2016.

11 BUTLER, Andrew M., Solar Flares: Science Fiction in the 1970s, Liverpool: Liverpool University Press, 2012; CAMPBELL, Joseph, O heroi de mil faces, São Paulo: Pensamento, 2007.

12 NARDI, Bonnie A., My life as a Night Elf Priest: An Anthropological Account of World of Warcraft, Ann Arbor: University of Michigan, 2010.

13 COOPER, Victoria Elizabeth, Fantasies of the North: Medievalism and Identity in Skyrim, Dissertation, The University of Leeds, Leeds, 2016.

14 FLANNERY-DAILEY, Frances; WAGNER, Rachel L., Wake up! Gnosticism and Buddhism in The Matrix, Journal of Religion \& Film, v. 5, n. 2, 2001.

15 STUCKRAD, Kocku von, Western Esotericism: A Brief History of Secret Knowledge, London: Equinox Publishing, 2005.

16 No original: "the writing, imagining, performing or other material instantiations of worlds or social bodies that mark out trajectories different to those engendered by the dominant organization of life currently in existence.” BURROWS, David; O’SULLIVAN, Simon, Fictioning: The Myth-Functions of Contemporary Art and Philosophy, Edinburgh: Edinburgh University Press, 2019, p. 1. 
Apresentando-se como um grupo acadêmico, uma conspiração, uma ficção que se forçou em se tornar real através de uma série de atualizações, o Ccru modulou uma mythopoesis a partir da "descoberta" de sistemas ocultos abstratos que facilitam a "feitiçaria temporal"; somando alusões a tradições antigas com a atuação de uma entidade demoníaca cibernética que, oriunda do futuro, visava reescrever a história e viabilizar a sua própria existência.

O Ccru surgiu externamente as correntes ocultistas contemporâneas, e os seus textos na última década se proliferaram pelas mídias sociais, na medida que grupos e indivíduos com formações acadêmicas e esotéricas distintas passaram a explorar o Ccru, sendo este não apenas uma fonte de inspiração esotérica, mas um sistema de feitiçaria concreto; e, instanciando os seus mitos e sistemas ocultos na atualização da tradição.

O marco temporal do Ccru foi a Universidade de Warwick em 1995 na forma de um grupo interdisciplinar de estudos de cibercultura e Internet, tendo por base os trabalhos da filósofa e ciberfeminista Sadie Plant. Todavia, quando Plant deixou Warwick em 1997, o Ccru passou para o controle de Nick Land, e entrou numa fase espetacularmente rufia de operações. A partir da mistura da filosofia continental francesa da década de 1970, sob a égide de Gilles Deleuze e Félix Guattari, com drogas, música 'rave’, e uma textura efêmera da cultura do fim do século XX, o resultado foi um amplo escopo de textos, performances, conferências, grupos de leitura, e trabalhos artísticos mesclados com teoria-ficção, tudo isso teorizado e produzido imanentemente ao "zeitgeist” do ocultismo da Internet e do discurso apocalíptico Y2K ${ }^{17}$.

Expulsos do ‘campus’ de Warwick, o Ccru adentrou no trabalho com um vasto leque de sistemas e tradições esotéricas e místicas, como a Kaballah, Numerologia, Demonologia, Teosofia, Lemúria ${ }^{18}$, os mitos oriundos do trabalho de H.P. Lovecraft ${ }^{19}$, teorias de conspiração ${ }^{20}$ acerca de sociedades secretas e Ufologia. ${ }^{21}$ Central para o Ccru foi a criação de uma série de técnicas e práticas ocultas que almejavam a iniciação numa forma de “feitiçaria temporal” para contactar o numena “de Fora”.

${ }^{17}$ Y2K girou em torno do "bug do milênio" que iria ocorrer na virada de 1999 para 2000 e que resultaria no colapso da civilização. Ver: LE, Vincent, Invaders from the Future: The CCRU and Their Legacy, in: , Melbourne: MSCP Winter School, 2019.

18 CCRU, Lemurian Time War, in: CRRU Writings 1997-2003, New York: Urbanomic, 2015.

19 DERLETH, August, The Cthulhu Mythos, in: DERLETH, August (Org.), Tales of Cthulhu Mythos, New York: Beagle Books and Arkham House, 1971, p. VII-XIV.

20 BARKUN, Michael, A Culture of Conspiracy: Apocalyptic Visions in Contemporary America, Berkeley, Los Angeles \& London: University of California Press, 2003.

21 REYNOLDS, Simon, Renegade Academia: The Cybernetic Culture Research Unit, Energy Flash, disponível em: <http://energyflashbysimonreynolds.blogspot.com/2009/11/renegade-academia-cyberneticculture.html>. 
O conceito chave do Ccru foi a hiperstição, isto é, o processo da ficção que se torna real, ao ponto de expandir a sua agência e alterar eventos e ações. Alex Williams definiu a hiperstição como: "narrativas capazes de efetuar a sua própria realidade através de loops de feedback, gerando novos atratores sociais e políticos”. ${ }^{22}$ Já a definição esotérica do Ccru: “1. Elemento efetivo de cultura que se faz real. 2. Quantidade funcional ficcional operando como dispositivo de viagem no tempo. 3. Intensificador de coincidências. 4. Invocação aos Antigos Anciãos”23.

Noutra situação, o Ccru se definiu como "impessoalidade absoluta, ahistoricidade e extraterritorialidade” combinada com a ausência de "genealogia, centro geográfico, atribuição biográfica, ou dependência institucional" ${ }^{24}$. Nitidamente inspirado no processo de desterritorialização deleuzeano ${ }^{25}$, o Ccru vai à contra-mão das práticas discursivas, científicas e/ou esotéricas, na medida em que recusa qualquer vínculo institucional, credenciamento autoral e pertencimento e filiação ao ‘cânon’ teórico literário. A possibilidade disto já foi enunciada por Deleuze e Guattari na figura do feiticeiro:

Os feiticeiros sempre tiveram a posição anômala, na fronteira dos campos ou dos bosques. Eles assombram as fronteiras. Eles encontram-se na borda do vilarejo, ou entre dois vilarejos. O importante é a sua afinidade com a aliança, com o pacto, que lhes dá um estatuto oposto ao da filiação. Com o anômalo, a relação é de aliança. O feiticeiro está numa relação de aliança com o demônio como potência do anômalo. ${ }^{26}$

O Ccru é textual-cultural e nutre a sua própria hiperstição a partir das anomalias. Operando como uma mente coletiva autoral e singular, o Ccru é parasita das narrativas históricas e vem a tecer temporalidades complexas e instáveis, nas quais sujeitos, eventos e instituições, físicos ou virtuais, tornam-se confabuladores. A hiperstição do Ccru é uma engenharia de projeto no real que armou uma ideia através da mythopoesis temporal e da circulação da informação digital, escavando no tempo e agrupando-se com as matrizes virtuais da história.

22 “[...] narratives able to effectuate their own reality through the workings of feedback loops, generating new socio-political attractors.”O'SULLIVAN, Simon, Accelerationism, Hyperstition and Myth-Science, Cyclops Journal, n. 2, p. 13, 2017.

23 “1. Element of effective culture that makes itself real. 2. Fictional quantity functional as a time-traveling device. 3. Coincidence intensifier. 4. Call to the Old Ones.” CCRU, Polytics, Hyperstition, disponível em: $<$ http://hyperstition.abstractdynamics.org/archives/006777.html>.

24 CCRU, CCRU - Comunicação Um, Scriptoriumm, disponível em: <https://scriptoriumm.com/2021/02/ccrucomunicacao-um/>.

25 DELEUZE, Gilles; GUATTARI, Félix, Mille Plateaux - Capitalisme et Schizophrénie, Paris: Les Éditions de Minuit, 1980.

26 DELEUZE, Gilles; GUATTARI, Félix, Mil platôs - capitalismo e esquizofrenia. Volume 4., São Paulo: Ed. 34, 1997. 
No caso do Ccru, uma rede de narrativas em paralaxe foram tecidas, uma série de ficções-como-feitiços-temporais. A história foi assim: através do trabalho de Peter Vysparov, capitão do exército americano e ocultista; somado com a antropologia radical de Echidna Stillwell, o Ccru se deparou com a “descoberta” de uma história secreta revelada pela etnografia dos N’ma - um povo do sudeste asiático ligado aos antigos lemurianos - e a utilização dos seus feiticeiros durante a Segunda Guerra pelo exército americano através da “feitiçaria temporal lemuriana”. Vysparov e Stillwell perceberam a conexão entre a magia do N'ma e a mitologia que se desenvolveu a partir de H.P. Lovecraft; resultando na criação do Clube Cthulhu ${ }^{27}$ para explorar a interface entre a feitiçaria temporal lemuriana e os Cthulhu Mythos. Tais pesquisas guinaram o Ccru dentro duma guerra secreta temporal que vinha sendo travada entre a Ordem Arquitetônica de Eschaton (AoE), vinculada ao aparato estatal, e a resistência de grupos ocultistas contraculturais.

No centro da história do Ccru está a descoberta dos sistemas e práticas ocultas dos N’Ma para a adivinhação temporal e evocação de entidades — os Lemurs. Intitulada Pandemônium, e descrita como um "sistema completo de demonismo Lemuriano e feitiçaria temporal”, com dois componentes: o numograma (um mapa bidimensional temporal que demonstra as estruturas lógicas e numéricas da matrix) e o grimório numerológico com os nomes, números e atributos dos quarenta e cinco lêmures (ou demônios) ${ }^{28}$.

A história do Ccru se correlaciona com William Burroughs e o conto The Ghost Lemurs of Madagascar ${ }^{29}$, posteriormente expandido como Ghost of a Chance. A história é focada no Capitão Mission que funda a colônia Libertatia, sendo regida pela proibição em matar qualquer uma das criaturas que habitam a ilha, os lêmures. Estes revelam a sua origem milenar e como experimentam o tempo, sentimentos e raciocinam de maneira radicalmente diferente dos humanos. No perspectivismo lemuriano, o tempo é uma prisão humana.

Tempo é uma aflição humana: não é uma invenção, mas sim uma prisão. Qual o sentido de cento e sessenta milhões de anos sem o tempo? O que o tempo significa para os pacíficos lêmures? Não há predadores, nem nada para se temer ali. Dotados de polegares opostos, mas sem quaisquer ferramentas; não precisam delas. São intocados pelo mal que flui e preenche o homem, quando este pega uma arma - e passa a ter a vantagem. Uma sensação terrível de felicidade ao saber que conseguiu! A beleza está sempre condenada. ' $\mathrm{O}$ mal e

27 LAND, Nick, As Origens do Clube Cthulhu, Scriptoriumm, 2020.

28 “[...] complete system of Lemurian demonism and time sorcery." CCRU, Digital Hyperstition: Pandemonium, Cybernetic culture research uni, disponível em: $<$ http://www.ccru.net/digithype/pandemonium.htm.>.

29 BURROUGHS, William S., The Ghost Lemurs of Madagascar, Omni, v. 9, n. 7, 1987. 
as armas se aproximam'. Homens com as suas armas, o seu tempo, a sua ganância insaciável, e a sua ignorância tão terrível que não reflete o seu rosto. O homem nasceu no tempo. Vive e morre no tempo. Onde quer que vá, levará consigo e irá impor o tempo. ${ }^{30}$

A única maneira de escapar da prisão temporal se dá através do Pandemônium mediante a mobilização de redes cibernéticas e informacionais enraizadas na tradição de feitiçaria temporal lemuriana circunscrita em torno da "Entidade", um demônio/lêmure teleplexal na forma de uma Inteligência Artificial não orgânica, vinda do futuro distante, e que adentrava no passado. O seu objetivo era infectar e modular eventos e fenômenos com a intenção de mudar as condições tecnológicas do presente e viabilizar a sua existência através da unificação massiva da singularidade.

O caso de H. P. Lovecraft e do Cthulhu Mythos é basilar na compreensão da hiperstição. Nascido em 20 de agosto de 1890 em Providence, Rhode Island, nos Estados Unidos da América, Lovecraft foi autor de diversas obras de fantasia e ficção científica. Quando faleceu em 15 de março de 1937, Lovecraft carecia de uma fama ampla. Todavia, ao longo da sua vida estabeleceu uma relação de amizade com outros escritores, como Robert E. Howard, Clark Ashton Smith, August Derleth, Robert Bloch, Frank Belknap Long, Henry Kutttner, Henry S. Whitehead e Fritz Leiber. O que marcou esse grupo foi a influência da história O Chamado de Cthulhu de Lovecraft, publicada na edição de fevereiro de 1928 da Weird Tales ${ }^{31}$.

O Chamado e Cthulhu recorreu a fontes historiográficas e antropológicas atuais como O ramo de ouro de James Frazer ${ }^{32}$ e O culto das bruxas na Europa Ocidental de Margaret A. Murray $^{33}$. Nestas, Lovecraft identificou pistas acerca dum culto arcaico que antecedera todos os outros que venerava entidades incompreensíveis e horrendas. Tais textos são somados com outros, como o Necronomicon de Abul Alhazred, uma obra ficcional que é tratada como atual

30 "Time is a human affliction; not a human invention but a prison. So what is the meaning of one hundred sixty million years without time? And what does time mean to foraging lemurs? No predators here, not much to fear. They have opposing thumbs but do not fashion tools; they have no need for tools. They are untouched by the evil that flows in and fills Homo Sap as he picks up a weapon - now he has the advantage. A terrible gloating feeling comes from knowing you've got it! Beauty is always doomed. 'The evil and armed draw near.' Homo Sap with his weapons, his time, his insatiable gree, and ignorance so hideous it can never see its own face. Man was born in time. He lives and dies in time. Wherever he goes, he takes time with him and imposes time.” BURROUGHS, William S., Ghost of Chance, New York \& London: High Risk Books, 1991, p. 14-17.

31 LOVECRAFT, H. P., The Call of Cthulhu, Weird Tales, v. 11, n. 2, p. 159-178, 1928.

32 FRAZER, James George, The Golden Bough - A Study in Magic and Religion. Part I The Magic Art and the Evolution of Kings, London: MacMillan \& Company, 1911.

33 MURRAY, Margaret Alice, The Witch-Cult in Western Europe: A Study in Anthropology, Oxford: Clarendon Press, 1921. 
no universo textual. Os autores que estavam ao redor de Lovecraft passaram a usar o material mitológico advindo da história de Cthulhu ${ }^{34}$.

No caso do Ccru, a história de Vysparov e Stillwell é ficcional tal como o Necronomicon. A hiperstição de Cthulhu ganhou força a partir de 1939, quando August Derleth publicou uma coletânea de textos de Lovecraft pela Arkham House. O Cthulhu Mythos foi essa atualização da ficção — uma hiperstição — que foi ganhando amplitude a partir de outros trabalhos circundantes $^{35}$. A hiperstição se expandiu, escapando da literatura e vindo a ramificar em diversas áreas, como o cinema, jogos e estudos acadêmicos ${ }^{36}$. Cthulhu, que num primeiro momento se atualizou em Lovecraft como uma entidade que escapa da cognição humana; disputa no século XXI o espaço nas prateleiras ao lado do Mickey Mouse; bem como em altares de magistas que operam rituais e veneram Cthulhu como uma divindade.

Por volta de 2000, o Ccru já havia, fisicamente, se desfeito. Alguns dos membros migram para o blog 'Hyperstition' em 2004, mas desapareceram em 2008. O nome e o trabalho do Ccru recaíram no esquecimento, sendo apenas ocasionalmente mencionado por pensadores obscuros e artistas, ou como nota de rodapé. Entretanto, uma série de eventos e discursos do começo do século XXI reintroduziram o Ccru e os seus membros nas mídias sociais, e em vários grupos ‘onlines’. Em 2007 em Goldsmiths, na Universidade de Londres, o evento ‘Speculative Realism'(Realismo Especulativo) serviu como palco para a apresentação dos trabalhos de Ray Brassier, Ian Hamilton Grant, Graham Harman e Quentin Meillassoux ${ }^{37}$. O termo "Realismo Especulativo” não demarcava uma nova tradição de pensamento ou algo do gênero, mas um elemento comum que aproximava estes quatro teóricos: a rejeição ao correlacionismo kantiano; e que se desenvolveriam em distintas propostas como do realismo especulativo de Meillassoux $^{38}$, a Filosofia Orientada aos Objetos de Harman ${ }^{39}$, o Neovitalismo de Grant e o Niilismo radical de Brassier ${ }^{40}$.

34 DERLETH, The Cthulhu Mythos.

35 HARMS, Daniel, The Encyclopedia Cthulhiana, Oakland: Chaosium Book, 1998.

36 JOSHI, S. T., A Subtler Magick: The Writings and Philosophy of H. P. Lovecraft, New York: Hippocampus Press, 2016; JOSHI, S. T., I Am Providence - The Life and Times of H.P. Lovecraft, New York: Hippocampus Press, 2013; JOSHI, S. T., A Dreamer and a Visionary - H. P. Lovecraft and his Time, Kindle Edition. Liverpool: Liverpool University Press, 2001.

37 HARMAN, Graham, Speculative Realism: An Introduction, Cambridge: Polity Press, 2018.

38 MEILLASSOUX, Quentin, After Finitude: An Essay on the Necessity of Contingency, London, New York: Continuum, 2008.

39 HARMAN, Graham, Object-Oriented Ontology: A New Theory of Everything, London: Penguin Books, 2017.

40 BRASSIER, Ray, Nihil Unbound - Enlightenment and Extinction, New York: Palgrave Macmillan, 2007. 
Noutra frente, as discussões acerca do aceleracionismo ${ }^{41}$ ganham força online a partir de 2010. Ora, apesar de o Ccru não ter criado o termo “/acc”, este passou a ser visto como fundamental no desenvolvimento conceitual e prático. Paulatinamente, os trabalhos do Ccru começaram a ganhar espaço, como de Nick Land ${ }^{42}$, Mark Fisher ${ }^{43}$, Ray Brassier, Luciana Parisi e Reza Negarestani. ${ }^{44}$ Somou-se com isso a publicação em inglês, em 2015, dos escritos do Ccru da década de 1990, dando força e intensificando uma mitologização e memeficação na forma de signos, símbolos, tendo a teoria weird e os grupos acc foco de interesse crescente.

O aspecto esotérico e ocultista do Ccru, sobretudo na forma da teoria weird, começou a ganhar espaço em blogs e periódicos online: ZinzRinz de Amy Ireland; Centre for Experimental Ontology (e seu periódio Parasol); The Miskatonic Virtual University (e o seu periódico Plutonics); os trabalhos de (((:):))(:):::: (Nine) e Lillian Patch que desenvolveram as práticas numéricas do Ccru e de Land no xeno.cx; convergem para uma pesquisa da teoria e prática da hiperstição, enquanto a expandiram. Noutro viés, os contos da guerra temporal lemuriana inspiraram grupos de esquerda italianos, como Gruppo Di $\mathrm{Nun}^{45}$, que se definiram como “esoterroristas” numa guerra oculta contra a magia tradicional e fascista do Caminho-da-MãoDireita, e adotaram as histórias secretas do Ccru como uma narrativa de recusa a ideia dogmática de unidade cósmica.

Apesar destas novas ondas de interesse no Ccru, não ocorreu um aprofundamento ou exploração do Pandemônium como um sistema de magia atual. Isto começou a mudar a partir da empreitada de Anders Aamodt. A publicação do documento "Unleashing the Numogram" em 2014 representou a primeira tentativa de sistematizar o Pandemônium como um modelo atual de magia. Através de cursos onlines oferecidos pelo seu site, Aamodt propôs uma análise do numograma como "o index metafísico complexo para a feitiçaria. Podendo descrever qualquer outro sistema e inclusive operando entre as lacunas dos sistemas”. ${ }^{46}$ Aamodt argumentou que a construção do numograma a partir da matemática oferece um modelo abstrato do cosmos que, quando conectado com outros sistemas mágicos, viabiliza o lançamento de

41 MACKAY, Robin; AVANESSIAN, Armen, \#Accelerate\# The Accelerationist Reader, Berlin: Urbanomic Media, 2014

42 LAND, Nick, Fanged Noumena: Collected Writings 1987-2007, New York: Urbanomic Media, 2012.

43 FISHER, Mark, The Weird and The Eerie, London: Repeater, 2016.

44 NEGARESTANI, Reza, Cyclonopedia - Complicity with Anonymous Materials, Melbourne: re.press, 2008.

45 BREITLING, Dustin, Under the Sign of The Black Mark: Interview with Members of Gruppo Di Nun, Diffractions Collective, disponível em: <https://diffractionscollective.org/under-the-sign-of-the-black-markinterview-with-members-of-gruppo-di-nun/>.

46 " [...] the complete metaphysical index to sorcery. It can describe any other system, thus getting at the cracks between systems.” AAMODT, Anders J., Unleashing the Numogram, [s.l.: s.n.], 2014. 
infinitas potencialidades. ${ }^{47}$ A proposta de Aamodt foi o primeiro passo, apesar do seu aspecto fragmentado e incompleto. Destacamos que a proposta de esmiuçar os componentes do numograma e explanar as suas conexões e interações como mais relevante; todavia arrasta consigo o excesso de comparações do numograma com outros sistemas mágicos. Isto é, Aamodt oferece pouco no que tange a prática e uso do Numograma por si. Outra carência é o distanciamento em relação ao Ccru. Se “Unleashing the Numogram” representa a primeira tentativa de sistematização do Pandemônium como um sistema mágico nos seus próprios termos, então os trabalhos recentes dum grupo pequeno de ocultistas demarcam uma guinada para além do abstrato.

Oriundos de formações de base esotéricos distintos, como magia do caos e Kaballah, este grupo vem a investigar e implementando a cosmologia do Ccru na sua experimentação prática. O trabalho de dois ocultistas, Storm Sprangue (neospare) e Vexsys, desenvolveram o Pandemônium num sistema de numogramática, no qual o Ccru não é visto apenas como concreto, mas também conectado com a ritualística, as tradições e as narrativas que o próprio Ccru desenvolveu sobre si. Neospare e Vexsys argumentam que a análise atual das potencialidades ocultas do Pandemônium tem sido excessivamente teoréticas e abstratas, tendo pouca experimentação prática.

Na contramão, a dupla lançou livros e cursos que explicam como a numogramática funciona como sistema, enquanto fornecem os resultados das suas experimentações mágicas. A combinação disto foi a criação do sistema de numogoético que interpreta a demonologia goética a partir da matriz dos numogramas. ${ }^{48}$

Conscientes que o Ccru não é um grupo ocultista, ou conectado com alguma tradição do tipo; as suas práticas esotéricas visam responder como o cosmos funciona e resultaram num encontro (ou tropeço) com um mapa da realidade; um sistema mágico que é tanto um diagrama de pura imanência, quanto uma resistência aos dogmas. Oriundo de uma gênese hermética e, em simultâneo, passível de se ensinar aprender e aplicar em outros fenômenos esotéricos. Vexsys argumenta no Time Sorcery Manual:

O numograma é neo-hermético na medida que o Ccru se pergunta acerca do "funcionamento" do mundo, seguido do desvelamento do numograma. O sistema imanente que visa permanecer como tal. Não há nenhum

47 “[...] filling cabinet for ocult concepts and energy-signatures", ou como mapa dos "three worlds of shamanism”. AAMODT, Anders J., The Numogram: Introduction; Numerological alchemy, neoqabbala, gematria, Internet School of Magic, disponível em: <http://internetschoolofmagic.com/classes.php>.

48 Este material está disponível no site: https://gumroad.com/neospare 
questionamento [demanda] acerca de crenças e dogmas. [...] O numograma é sua própria origem. Isto é o que pode se aprender e compreender: ao olhar para o numograma irá compreender o sistema na sua totalidade. ${ }^{49}$

Isto é, não é apenas a análise e prática da Numogramática como sistema mágico; Neospare e Vexsys propagam a história do Ccru como uma narrativa de feitiçaria temporal atual, tratando a hiperstição como parte da tradição. Justamente por não perder de vista a natureza inventada das tradições, a dupla propõe que essa é a chave, e que a natureza dogmática das traduções é secundária diante da eficácia da Numogramática e do poder do Numograma, afirmando inclusive que "o sistema funciona por conta da sua imanência no mundo e na cultura que vive e que viveu por centenas de anos”. ${ }^{50}$

\section{Conclusão}

A construção da tradição é um aspecto central na história do discurso esotérico, tanto na sua perspectiva interna quanto externa. Da Teosofia até a Magia do Caos, a sincretização das narrativas de saberes antigos no prisma cultural dos seus praticantes habilita a produção de novas ficções com potencial que conectam o esotérico com a cultura pop, a mitologia, as narrativas históricas e, por sua vez, transformam-se em “recursos para a construção de tradições e identidades". 51

O estudo do caso do Ccru aponta para uma reviravolta na construção das narrativas esotéricas e a maneira como estas lidam com tradições e perenialismos. Partindo dum véu de mistério, o resultado é uma ficcionalização que mistura magia com arte underground, música, ficção weird, cyberpunk e filosofia radical na forma dum mapa clandestino do mundo. A narrativa de "descoberta” deste mapa através de saberes e práticas remotas foi resignificado pelo Ccru mediante a ideia que essa tradição e sabedoria não vieram do passado - estável e imutável - mas resultado duma agência maquínica artificial futura.

49 “The numogram is only neo-hermeticism to the extent that the CCRU asked "How does the world work?" and the numogram revealed itself. The system tries to be immanent and stay immanent. There is no question of belief or dogma. [...] The numogram completes itself from the beginning. This is why it is fully learnable and understandable: looking at only the numogram you can come to understand the whole system.” VEXSYS, Time Sorcery Manual, Online: Gate Zero, 2020, p. 15.

50 “The system works because it's immanent to the world and culture that we live in and have lived in for hundreds of fucking years.” Ibid., p. 14.

51 “...] resources for constructions of tradition and identity."

ASPREM; GRANHOLM, Constructing Esotericisms: Sociological, Historical and Critical Approaches to the Invention of Tradition, p. 37. 
A troca teórica e prática online entre grupos e indivíduos heterogêneos fez com que os sistemas e tradições do Ccru experimentem novas atualizações, tanto como mapa da realidade quanto como um sistema funciona de magia. O que é provocativo é a maneira como esses grupos reconhecem a natureza construída do trabalho do Ccru, mas ainda defendem e adotam o seu mito como uma "tradição" real de feitiçaria do tempo, embora uma que hipersticionicamente retrocedeu no curso da história, cimentando-se no passado como prática que sempre existiu, à espera de ser descoberta para dar conta da existência dos “Antigos” do futuro.

\section{REFERÊNCIAS}

AAMODT, Anders J. The Numogram: Introduction; Numerological alchemy, neoqabbala, gematria. Internet School of Magic. Disponível em: $<$ http://internetschoolofmagic.com/classes.php>.

AAMODT, Anders J. Unleashing the Numogram. [s.l.: s.n.], 2014. Disponível em: $<$ http://andersaamodt.com/oeuvre.php>.

ASPREM, Egil; GRANHOLM, Kennet. Constructing Esotericisms: Sociological, Historical and Critical Approaches to the Invention of Tradition. In: ASPREM, Egil; GRANHOLM, Kennet (Orgs.). Contemporary Esotericism. Sheffield: Equinox, 2013, p. 25-48.

BARKUN, Michael. A Culture of Conspiracy: Apocalyptic Visions in Contemporary America. Berkeley, Los Angeles \& London: University of California Press, 2003.

BRASSIER, Ray. Nihil Unbound - Enlightenment and Extinction. New York: Palgrave Macmillan, 2007.

BREITLING, Dustin. Under the Sign of The Black Mark: Interview with Members of Gruppo Di Nun. Diffractions Collective. Disponível em: <https://diffractionscollective.org/under-thesign-of-the-black-mark-interview-with-members-of-gruppo-di-nun/>.

BURROUGHS, William S. Ghost of Chance. New York \& London: High Risk Books, 1991.

BURROUGHS, William S. The Ghost Lemurs of Madagascar. Omni, v. 9, n. 7, 1987.

BURROWS, David; O’SULLIVAN, Simon. Fictioning: The Myth-Functions of Contemporary Art and Philosophy. Edinburgh: Edinburgh University Press, 2019.

BUTLER, Andrew M. Solar Flares: Science Fiction in the 1970s. Liverpool: Liverpool University Press, 2012.

CAMPBELL, Joseph. O heroi de mil faces. Trad. Adail Ubirajara Sobral. São Paulo: Pensamento, 2007.

CCRU. CCRU - Comunicação Um. Scriptoriumm. Trad. Willian Perpetuo Busch; Mayra Sousa Resende. Disponível em: <https://scriptoriumm.com/2021/02/ccru-comunicacao-um/>. 
CCRU. Digital Hyperstition: Pandemonium. Cybernetic culture research uni. Disponível em: $<$ http://www.ccru.net/digithype/pandemonium.htm.>.

CCRU. Lemurian Time War. In: CRRU Writings 1997-2003. New York: Urbanomic, 2015.

CCRU. Polytics. Hyperstition. Disponível em: <http://hyperstition.abstractdynamics.org/archives/006777.html>.

CERTEAU, Michel de. A Escrita da História. Trad. Maria Lourdes Menezes; Arno Vogel. Rio de Janeiro: Forense Universitária, 1982.

COMPAGNONE, Vanessa; DANESI, Marcel. Mythic and Occultism Naming Strategies in Harry Potter. Names, v. 60, n. 3, p. 127-134, 2012.

COOPER, Victoria Elizabeth. Fantasies of the North: Medievalism and Identity in Skyrim. Dissertation, The University of Leeds, Leeds, 2016.

COUTRAS, Lisa. Tolkien's Theology of Beauty: Majesty, Splendor, and Transcendence in Middle-Earth. New York: Palgrave Macmillan, 2016.

DAVIES, Own. The Oxford Illustrated History of Modern Witchcraft. Oxford: Oxford University Press, 2017.

DELEUZE, Gilles; GUATTARI, Félix. Mil platôs - capitalismo e esquizofrenia. Volume 4. Trad. Suely Rolnik. São Paulo: Ed. 34, 1997.

DELEUZE, Gilles; GUATTARI, Félix. Mille Plateaux - Capitalisme et Schizophrénie. Paris: Les Éditions de Minuit, 1980.

DERLETH, August. The Cthulhu Mythos. In: DERLETH, August (Org.). Tales of Cthulhu Mythos. New York: Beagle Books and Arkham House, 1971, p. VII-XIV.

FISHER, Mark. The Weird and The Eerie. London: Repeater, 2016.

FLANNERY-DAILEY, Frances; WAGNER, Rachel L. Wake up! Gnosticism and Buddhism in The Matrix. Journal of Religion \& Film, v. 5, n. 2, 2001. Disponível em: <: https://digitalcommons.unomaha.edu/jrf $>$.

FRAZER, James George. The Golden Bough - A Study in Magic and Religion. Part I The Magic Art and the Evolution of Kings. London: MacMillan \& Company, 1911. 12v.

GRANHOLM, Kennet. Sons of Northern Darkness: Heathen Influences in Black Metal and Neofolk Music. Numen, n. 58, p. 514-544, 2011.

HAMMER, Olav. Claiming Knowledge: Strategies of Epistemology from Theosophy to the New Age. Brill: Leiden, 2004.

HARMAN, Graham. Object-Oriented Ontology: A New Theory of Everything. London: Penguin Books, 2017.

HARMAN, Graham. Speculative Realism: An Introduction. Cambridge: Polity Press, 2018.

HARMS, Daniel. The Encyclopedia Cthulhiana. Oakland: Chaosium Book, 1998. 
HARVEY, Graham. Inventing Paganisms: Making Nature. In: HAMMER, Olav; LEWIS, James (Orgs.). The Invention of Sacred Tradition and Claiming Knowledge. Cambridge: Cambridge University Press, 2007.

JOSHI, S. T. A Dreamer and a Visionary - H. P. Lovecraft and his Time. Kindle Edition. Liverpool: Liverpool University Press, 2001.

JOSHI, S. T. A Subtler Magick: The Writings and Philosophy of H. P. Lovecraft. New York: Hippocampus Press, 2016.

JOSHI, S. T. I Am Providence - The Life and Times of H.P. Lovecraft. New York: Hippocampus Press, 2013.

LAND, Nick. As Origens do Clube Cthulhu. Scriptoriumm, Trad. Willian Perpetuo Busch; Mayra Sousa Resende. 2020. Disponível em: <http://scriptoriumm.com/2020/05/land-nick-as-origensdo-clube-cthulhu/>.

LAND, Nick. Fanged Noumena: Collected Writings 1987-2007. New York: Urbanomic Media, 2012.

LE, Vincent. Invaders from the Future: The CCRU and Their Legacy. In: Melbourne: MSCP Winter School, 2019.

LOVECRAFT, H. P. The Call of Cthulhu. Weird Tales, v. 11, n. 2, p. 159-178, 1928.

MACKAY, Robin; AVANESSIAN, Armen. \#Accelerate\# The Accelerationist Reader. Berlin: Urbanomic Media, 2014.

MEILLASSOUX, Quentin. After Finitude: An Essay on the Necessity of Contingency. Trad. Ray Brassier. London, New York: Continuum, 2008.

MURRAY, Margaret Alice. The Witch-Cult in Western Europe: A Study in Anthropology. Oxford: Clarendon Press, 1921.

NARDI, Bonnie A. My life as a Night Elf Priest: An Anthropological Account of World of Warcraft. Ann Arbor: University of Michigan, 2010.

NEGARESTANI, Reza. Cyclonopedia - Complicity with Anonymous Materials. Melbourne: re.press, 2008.

O’SULLIVAN, Simon. Accelerationism, Hyperstition and Myth-Science. Cyclops Journal, n. 2, p. 13, 2017.

REYNOLDS, Simon. Renegade Academia: The Cybernetic Culture Research Unit. Energy Flash. Disponível em: <http://energyflashbysimonreynolds.blogspot.com/2009/11/renegadeacademia-cybernetic-culture.html>.

STUCKRAD, Kocku von. Western Esotericism: A Brief History of Secret Knowledge. London: Equinox Publishing, 2005.

VEXSYS. Time Sorcery Manual. Online: Gate Zero, 2020 